\title{
A Theoretical Study on the Rational Behavior of Users' Credit Compliance Willingness
}

\author{
Dongmei Xia and Yougui Zhao \\ Chongqing institute of engineering, Chongqing, China
}

\begin{abstract}
In the field of credit research, there are relatively few studies that build a model from the perspective of TTF model and TAM model integration. The research will combine TTF and TAM to build a structural model with credit user type as the regulating variable. The research is carried out with tasktechnology fit, social influence, ease of use, usefulness, psychological contract, willingness to perform the contract, credit user type and other variables, which is innovative in the construction of the model.
\end{abstract}

Keywords-credit; TTF model; TAM model; psychological contract

\section{INTRODUCTION}

China Banking and Insurance Regulatory Commission pointed out that the current form of risks facing the bancassurance industry is still complicated and severe. On the one hand, Banks still need to further dispose of extremely bad loans; on the other hand, credit risks are still emerging in 2019. In this context, how can Banks, financial leasing companies and other financial institutions guide users to actively implement contracts so as to better promote the development of enterprises. How to promote credit users to perform actively on the technical level is particularly important. "Self-performance contract" emphasizes that the performance of contract does not depend on the third party enforcement, but relies on the private performance cost. To be specific, continuous performance is a dynamic and circular process, as well as a purposeful and subjectively driven behavior pattern. It starts from contractual relationship, so as to make efforts to realize "selfperformance". At the same time, the continuous repayment of users is an essential support for the business development, but also an important factor to enhance social integrity. Therefore, at the technical level, financial institutions can adopt reasonable ways to promote users' willingness to fulfill the contract and reduce business risks.

The research was carried out based on rational behavior theory and relevant theories of self-performance agreement, and combined with credit users in chongqing. Through the task technology fit model (the vera.ttf), the technology acceptance model (TAM), use intention, psychological contract, and the performance will as the research variables to carry out the study, to explore the task technology fit model, technology acceptance model with the mechanism of action of the performance will financial credit users, are also under the guidance of the theory of rational behavior task technology fit model, on the technology acceptance model with user credit behavior to do some try.
Research in the theory of rational behavior at home and abroad for reference, the task technology fit model, technology acceptance model, and the advanced experience of the theory of self performance agreement, chain in chongqing three gorges bank in chongqing area, integrating science and technology enterprise credit user as the research object in the task technology fit model (the vera.ttf), the technology acceptance model (TAM), use intention, psychological contract, and the performance of the will of role relationship, study the mechanism of action between users, tasks, technology, to a major QingDianXing financial institutions provide reasonable guidance. Studying these problems can make strategies for enterprises from the aspects of technology, task and user management, improve users' willingness to fulfill the contract and relieve the pressure of enterprise management, which is of great practical significance.

\section{RESEARCH STATUS}

\section{A. Task-technology Fit Model (TTF)}

Goodhue \& Thompson (1995) proposed a task-technology adaptation model based on the early technology-performance chain (TPC) model. Study Task characteristics and Technology features are key elements of the Task Technology fit and performance, its core idea is the use of Technology products and its using effect depends largely on the Task - Technology adaptation, joined the individual features in the subsequent research and that the individual characteristics through the Task - technical characteristic, in turn, affect the using performance, form the final the vera.ttf model is shown in figure 1. Tasktechnology Fit Model (TTF) can effectively explain user behavior and its performance, and discuss the factors that the adaptation between Technology and Task affects user behavior. Therefore, only the information Technology suitable for the Task is the best. At present, TTF is widely applied in various fields, including technological innovation (Irum and Ismail,2017), commercial bank (Abbas et al.,2018), information processing (Chen,2019), network directional behavior (jiang yushi,2017), etc.

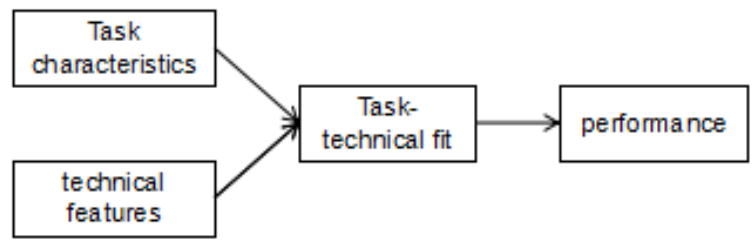

FIGURE I. TASK-TECHNOLOGY FIT MODEL 


\section{B. Technology Acceptance Model (TAM)}

Prediction of user behavior has always been one of the main purposes of psychological theoretical research. Some theories on prediction of user behavior include Fishbein \& Ajzen's (1975) Theory of reasoned action (TRA) and Davis's (1989) Technical Acceptance Model (TAM). TAM model, based on the theory of planned behavior, is a powerful tool used to describe users' information technology acceptance problems (Agarwal and Prasad, 1999; Davis,1989), and its structural model is shown in figure 2 .

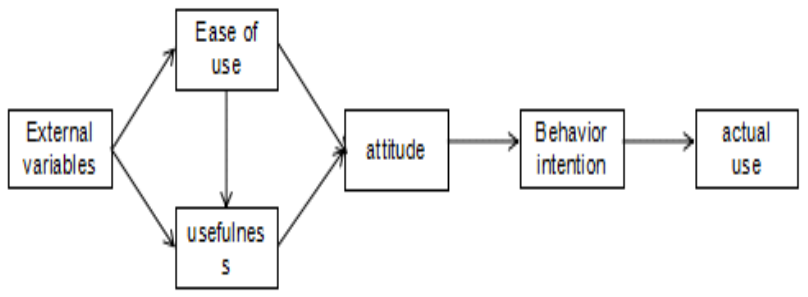

FIGURE II. TECHNOLOGY ACCEPTANCE MODEL

In the original TAM model, the two "perception" structures proposed affect the behavioral intention of users through the attitude of using technology, and then affect the actual use of users. In the subsequent TAM extension model, many empirical studies have proved that perceived usefulness (PU) and perceived ease of use (PEOU) are significantly correlated with users' actual use. Over the years TAM model has been widely verified in application and extension and has good predictive validity in the use of information technology in other fields. Including family financing (Aliet al.,2017), e-bank (munoz-leiva al.,2017), network shopping (Sharma and Bhatt,2018), mobile payment (lu wenjuan, wang yihan,2017), etc.

\section{Psychological Contract}

Argyris in the $1960 \mathrm{~s}$ in its understanding of organizational behavior, put forward the relationship between psychological contract is hidden in the heart of a kind of way, mainly psychological contract management and the ties between the two at the grass-roots level, psychological contract is to be able to give employees in personal expectations, or employees can gain something from the organization of a kind of belief structure. Baker (1985) proposed that psychological contract is not only implicit, but also has the characteristics of explicit contract in some stages. Psychological contract includes written and unwritten, explicit and unexpressed expectations.

There is a distinction between the broad and the narrow definition of psychological contract. In a broad sense, the process of psychological contract exchanging issues with each other from various systems and forms focuses on the understanding of obligations in their relationship, which can pay more attention to psychological components. From another perspective, psychological contract is a commitment and perception based on understanding, focusing on the mutual obligations both of them are aware of (Yang shuang,2014; Chen xiaozhou,2018; Tekleab et al.,2019). The generation and maintenance of psychological contract are mainly affected by some factors. They are :(1) prior negotiations. That is, before the contract is established, the negotiation of exchange relationship is the basis for forming psychological contract (Lemmon et al.,2016). (2) maintain fairness and dynamic balance of contracts. At the same time, the play of the role of psychological contract is realized through a series of processes such as its formation, performance and rupture, and the communication mode throughout the whole process of psychological contract plays an important role in the play of the role of psychological contract (Harrington and Lee, 2015).

\section{Self Performance Contract}

Performance of contract is a kind of behavior and a positive manifestation of contractual relationship. In general, selfperformance contract refers to the fact that the performance of contract does not depend on the third party enforcement but relies on the private performance cost. Helsel (1981) referred to this contract as "pure self-performance contract". Self performance is an implicit contract. It can be a contract reached by both parties with common knowledge, or a consensus reached through communication or communication, which is performed voluntarily by the parties without the intervention of a third party, and it can be in oral or written form (North and Wallis, 1994).

Since the contract is self-performing without the intervention of a third party, the breach of one party to the contract is entirely dependent on the judgment of the other party. The self-enforcing mechanism of contract refers to a mechanism that relies on private automatic implementation without the intervention of a third party. Self-enforcing mechanism is a market mechanism that relies on goodwill, trademarks, customs and reputation to ensure the self-enforcing of contracts. When one party to the transaction defaults, the other party terminates the contract and loses future quasi-rents. When the discount value of future quasi-rent is greater than the short-term benefit of breach of contract, the contractor will choose to perform the contract to obtain future quasi-rent flow (Klein, 1985). The performance is usually focused on tax enforcement (Pomeranz, 2015), government rules (Yared, 2018), commercial Banks (Avci et al.,2019), and commercial loans (mi yunsen et al., 2017).

\section{RELATION OF VARIABLES}

\section{A. Task Technology Adaptability and Usefulness, Ease of Use, Willingness to Use}

Task-technology adaptation theory suggests that the use of technology may lead to different results depending on its configuration and task. TTF depends on the adaptation degree between task requirements and technical functions. A good TTF can promote users to search for key information by APP, while a poor TTF adaptation will reduce users' willingness to adopt (zhang kun et al., 2016). Obviously, if the use of a product or platform fails to meet users' expectations, it will be 
ignored by users because of its lack of perceived usefulness (Kosturki \& Skornia,2011). Therefore, TTF has an important impact on users' perceived usefulness, which further influences users' willingness to adopt. Abbas et al. (2018) pointed out that TTF can influence users' use of information technology, which proved the importance of TTF to users' adoption. In TTF model, task and technology are the logical preconditions of TTF. Xu and Huang (2018) believe that a good TTF intelligent information system will promote the willingness of tourists to use the platform. It can be concluded that task technology adaptation will affect users' perceived usefulness, ease of use and willingness to use.

\section{B. Usefulness, Ease of Use, Attitude and Willingness to Use}

According to TAM technology acceptance model, perceived usefulness and perceived ease of use are two important aspects that affect users' attitude towards use. Users expect to gain more valuable content with the least effort when using this new technology (Samuel et al.,2018). Perceived usefulness is the assumption that a user's use of an application improves their performance within the organization. Bhattacherjee (2001) argues that users will continue to use the application when they feel it is useful. Perceived ease of use is the belief that users expect the least effort to use an application.

AlKailani (2016) pointed out that perceived usefulness and perceived ease of use had positive effects on usage intention when bank users used network banking services. Indian students' perceived usefulness and ease of use in the use of ebanking services have a positive impact on willingness to use (Kumar and Lall,2018). Shima and Mohamadali (2018) used TAM model and TPB model to carry out users' willingness to use electronic banking, and perceived usefulness had a positive impact on users' actual use, thereby affecting their actual use behavior. Users use e-banking platform in order to obtain required and useful resources and services. Therefore, as long as users feel useful, they will adopt the services provided by the platform. There is a clear influence relationship between perceived usefulness and perceived ease of use in TAM model, that is, the easier the user can master the technology and the more convenient it is to use the technology, the more useful the user will think the technology or system. Based on TAM, this paper empirically analyzes the influencing factors of farmers' willingness to use $\mathrm{P} 2 \mathrm{P}$ online lending platforms in wenjiang. The results show that perceived ease of use significantly affects perceived usefulness, and thus attitude. Therefore, it can be found that the ease of use of the technology platform will affect the usefulness, and the usefulness and ease of use will also affect the attitude of use.

\section{The Relationship between Social Influence and Usefulness and Willingness to Use}

Social influence, as an external variable, reflects the situation that users use online bank credit services. Lu et al. (2005) pointed out that social influence can alleviate users' uncertainty about the adoption of innovative technologies. Such social influence comes from the evaluation of social network or the attitude of important people towards new technologies, which leads to the change of trust tendency. If the object of the user's trust chooses to adopt the technology, it greatly increases the likelihood that the user itself will adopt the intention. Social influence originates from the conformity psychology of users, which is the key factor that causes important task use behavior to affect users' use intention. Wu lili and li gucheng (2016) verified the influence of social influence variables on perceived usefulness from the perspective of labor saving technology. Slade et al. (2015) found from the perspective of P2P private lending that social influence would have a positive impact on users' use of the platform. It can be argued that social impact, as an external variable, will have a positive impact on the usefulness of products and the willingness to use technology platforms.

\section{The Relationship between Use Intention, Psychological Contract and Performance Intention}

Willingness to use refers to the subjective probability and possibility of an individual to engage in certain behaviors. Peter and Olson (1996) defined willingness to use as the specific behaviors and holding tendencies that users may adopt towards their favorite products. In the field of social psychology, it has been proved that attitude can affect user's behavior. In management, user's attitude, as an important influencing factor, responds to user's behavior. In the TTF and TAM models, usage behavior is defined as the user's use of a new device, system, or technology operation. In fact, whether performance or breach is similar to the use behavior in TTF and TAM model, the use intention is also the behavioral intention (Davis,1989; Fishbein,1975). Therefore, combined with TTF and TAM model, individual users' willingness to use a specific platform may affect their choice of performance and breach of contract. At the same time, psychological contract as a mutual obligation will affect individual commitment and civic behavior. (Kickul, 2001; Turnley \& Feldman, 2000). Guest (2016) found in his study that psychological contract would affect people's commitment behavior. Wang meng (2018) found in his research that the improvement of psychological contract could greatly enhance the commitment intention of individuals. One of the most direct negative emotional reactions to the rupture of psychological contract is the breach of psychological contract. Previous studies have shown that the breach of psychological contract is positively correlated with the breach of psychological contract (Zhao et al., 2007). Li chui (2013) personal will has a positive impact on psychological contract. Moreover, the breach of psychological contract will significantly affect the participants' willingness to breach the contract. It can be considered that once the psychological contract of the user group is broken, the risk of default will be greatly increased.

\section{PlatForm STRUCTURE}

\section{A. Hardware Part}

The outline model of the credit platform comprehensive information management system is shown in figure 1, which provides setting key, upper and lower key, confirming key, return key and reset key. Press the Settings key to realize different functions, and then press the up and down key to select height (pressure) measurement, temperature measurement, etc. Then press ok, you can enter a different 
three on the platform. Therefore, the research needs to use a more systematic integration model to explain and predict users' performance behavior from multiple dimensions and perspectives.

\section{PROJECT FUNDS}

Supported by the Science and Technology Research Program of Chongqing Municipal Education Commission (Grant No. KJZD-M201901901)

Supported by the Science and Technology Research Program of Ba'nan District Commission “Design and Research of Electromagnetic Resonance Coupled Wireless Charging System for Electric Vehicle”

This paper is funded by chongqing education science planning project (project no. 2017-gx-035).

\section{REFERENCES} graphic lattice, which can display Chinese characters and graphics, with built-in 8192 Chinese characters (16*16 lattice), 128 characters $(8 * 16$ lattice) and 64*256 lattice display RAM, power supply VDD: $3.3 v \sim+5 V$ (built-in boost circuit, no negative pressure). Mainly provide display, is to collect the signal, and then display through the MCU. To provide picture and text information, compass we use a circle marked with directions, using the compass to divide 360 different directions.

\section{B. Software}

Gas detection: we use the MQ - 135 gas sensor, MQ135 sensor for ammonia, sulfur, benzene series steam of high sensitivity, of smoke and other harmful detection is ideal, it is related to gas in the air can be converted to electrical signals, the sensor produced by the electrical signal by the electronic circuit after processing, amplification and conversion, can display and alarm on gas. The measuring circuit consists of a test circuit and a heating circuit. In the test loop, the surface resistance of the sensor changes with the concentration of the gas to be measured, and the concentration of the gas to be measured in the air is reflected by the output of the effective voltage signal on the load in series with it.

With the MCU HT46R24 packaged by SKDIP/SOP as the main control CPU, it internally provides 8-channel and 10-bit resolution A/D conversion. 2-channel 4-bit PWM highfrequency carrier output; I2C bus serial interface; Programmable frequency divider PFD, etc., easy to use. The algorithm flow chart of each part of the system is as follows:

\section{CONCLUSION}

As can be seen from the above literature, existing studies have investigated the willingness of users of different credit platforms from different perspectives, and the research model is relatively single. The research on users' performance behavior mostly focuses on the level of psychological contract rupture, which is not comprehensive enough. The technology, task and users of credit service platform are interdependent and interactive. Users of different platforms need to accomplish different tasks, and a single model cannot systematically explain the relationship among the three, nor the impact of the
[1] Thompson G R L. Task-Technology Fit and Individual Performance[J]. MIS Quarterly, 1995, 19 (2) :213-236.

[2] Irum S, Ismail K, Ashfaq M. Factors Influencing Post Adoption Behaviour of Technological Innovation[J]. Advanced Science Letters, 2017, 23 (9) : 8939-8941.

[3] Abbas S K, Hassan H A, Asif J, et al. Integration of TTF, UTAUT, and ITM for mobile Banking Adoption[J]. International Journal of Advanced Engineering, Management and Science, 2018, 4 (5) : 89-101.

[4] Ali M, Raza S A, Puah C H, et al. Islamic home financing in Pakistan: a SEM-based approach using modified TPB model[J]. Housing Studies, 2017, 32 (8) : 1156-1177.

[5] Munoz-Leiva F, Climent-Climent S, Liébana-Cabanillas F. Determinants of intention to use the mobile banking apps: An extension of the classic TAM model[J]. Spanish Journal of Marketing-ESIC, 2017, 21 (1) : 2538.

[6] Sharma B K, Bhatt V K. Impact of Social Media on Consumer Buying Behavior-A Descriptive Study on Tam Model[J]. i-Manager's Journal on Management, 2018, 13 (1) : 34.

[7] He yong, dong yiyun. Journal of hunan university of technology (social science edition). 2019(02)

[8] Merton default distance model's ability to predict corporate financial distress -- an empirical analysis based on discrete time risk model [J]. CAI yulan, cui yi. Forecast. 2015(06)

[9] are farmers' credit defaults voluntary? -- mechanism of farmers' credit default in the state of asymmetric information [J]. Su zhi, hu di. Management world. 2014(09) 